\title{
An Examination of the Processes by Which Construal Level Affects the Implicit Evaluation of Goal Relevant Stimuli
}

AQ: au

\author{
Heather R. Rees \\ University of California, Davis
}

H. Anna Han

National Institutes of Health, Rockville, Maryland

\author{
Kentaro Fujita \\ The Ohio State University
}

Jeffrey W. Sherman

University of California, Davis

\author{
Asael Y. Sklar \\ The Ohio State University
}

\begin{abstract}
Previous research has found that construal level—how abstractly or concretely people represent events - can impact implicit evaluations. Abstract high-level construal (vs. concrete low-level construal) promotes evaluative responses consistent with global (strongly held, long-term) rather than local (short-term, situational) goals. It remains unclear by what cognitive process(es) this occurs. In this paper, we examine two possibilities. High-level construal might enhance the unintended influence of activated evaluative associations or facilitate the detection and implementation of intentional responses. To examine these possibilities, the current study applies a multinomial processing tree model to data from Fujita and Han (2009). Results suggest that high-level construal facilitates goal-consistent evaluations by increasing both the unintentional influence of activated goal-consistent positive associations and the intentional detection of and implementation of accurate responding to goal-relevant stimuli. These findings extend our understanding of how construal level promotes goal consistent evaluations.
\end{abstract}

Keywords: self-control, implicit associations, construal level, goal pursuit

Researchers have long been interested in selfcontrol-decision-making that favors the pursuit of long-term global goals over short-term

AQ: 4 Heather R. Rees, Department of Psychology, University of California, Davis; Kentaro Fujita, Department of Psychology, The Ohio State University; H. Anna Han, Behavioral Science, National Institutes of Health, Rockville, Maryland; Jeffrey W. Sherman, Department of Psychology, University of California, Davis; Asael Y. Sklar, Department of Psychology, The Ohio State University.

Preparation of this article was partially supported by an Anneliese Maier Research Award from the Alexander von Humboldt Foundation to Jeffrey W. Sherman, and grants from the National Science Foundation $(0817360$, 1626733) and The John Templeton Foundation (Prime Award 15462, Sub-Award SC18) to Kentaro Fujita.

Correspondence concerning this article should be addressed to Heather R. Rees, Department of Psychology, University of California, 1 Shields Avenue, Davis, CA 95616. E-mail: hrrees@ucdavis.edu local temptations (Ainslie, 1975; Fujita, 2011; Mischel, Shoda, \& Rodriguez, 1989). Many researchers have suggested that self-control entails the effortful inhibition of impulses, and as such, requires access to sufficient cognitive resources (Hinson, Jameson, \& Whitney, 2003; Hofman, Friese, \& Strack, 2009; Inzlicht \& Gutsell, 2007; Muraven \& Baumeister, 2000; Shiv \& Fedorikhin, 1999; Strack \& Deutsch, 2004). However, there has been accumulating evidence that individuals can pursue global goals in the presence of local situational demands even when cognitive resources are restricted. That is, given sufficient motivation, people can develop efficient responses to stimuli that advance rather than undermine global motivations. For example, individuals with chronically active egalitarian goals are capable of making nonprejudiced evaluative responses to stimuli that refer to stigmatized minorities, even on implicit measures-tasks that restrict 
the influence of deliberate, resource-dependent processes (Devine, Plant, Amodio, HarmonJones, \& Vance, 2002; Gonsalkorale, Sherman, Allen, Klauer, \& Amodio, 2011; Moskowitz, 2002; Moskowitz, Gollwitzer, Wasel, \& Schaal, 1999). Similar effects on implicit evaluations have been shown with other goals, such as weight loss (Fishbach \& Shah, 2006; Fishbach, Zhang, \& Trope, 2010). It seems that if individuals have strongly held goals, they may evaluate stimuli in a way that is consistent with such goals, even when their resources are restricted. In turn, goal-congruent implicit evaluations of goal-relevant stimuli facilitate goal-congruent behavior (Fujita, 2008; Fujita \& Carnevale, 2012).

\section{Construal Level and Self-Control}

Research indicates that an important factor in determining people's implicit evaluations of tempting stimuli is construal level. Individuals can represent events at varying levels of abstractness, focusing either on incidental, context-specific features (i.e., low-level construal) or more essential, generalized features (i.e., high-level construal). Construal level theory proposes that high- and low-level construal represent a functional response to the challenge of representing events that are psychologically distant versus near, respectively (Trope \& Liberman, 2010). Psychological distance refers to the removal of an event from direct experience. For example, an event that will occur a year from now or in another country is psychologically distant relative to an event that will occur tomorrow or in a town where one lives. People lack reliable information about concrete specifics about psychologically distant events. In response to this problem, construal level theory suggests that they represent these events by engaging in high-level construal-representing events in terms of their core and essential features; a process referred to as high-level construal. This is functional because an event's essential features tend to be stable and invariant across all possible manifestations. As concrete specifics become more available and reliable with increasing psychological proximity, people use this information to create detailed and idiosyncratic representations of events; a process referred to as low-level construal. This allows people to tailor their thoughts, feelings, and behavior to the unique demands of the specific event. Thus, a hiking trip in the distant future might be represented as "communing with nature," and the same trip in the near future might instead be represented as "walking up this big hill with this heavy backpack in this wet weather."

Extensive research supports the notion that people represent events that are psychologically distant versus near via high-level versus low-level construal, respectively (for a review, see Trope \& Liberman, 2010). Importantly, research suggests that the opposite may be true as well-that is, engaging in high-level versus low-level construal may attune people to concerns that extend beyond immediate direct experience. For example, manipulating construal level directly leads people to be more concerned about their more abstract goals and values rather than more immediate pragmatic concerns (e.g., Torelli \& Kaikati, 2009). In the context of selfcontrol, inducing high-level versus low-level construal promotes preferences for outcomes consistent with long-term goals rather than short-term temptations (e.g., Fujita, 2008; Fujita \& Carnevale, 2012). When those concerned about weight-loss, for example, are engaged in high-level rather than low-level construal, they are more likely to evaluate food temptations relatively negatively and report diet-consistent food preferences (Fujita \& Han, 2009).

Of note, these changes in evaluation as a function of construal level are evident even when they are assessed using implicit measures, such as the Implicit Association Test (IAT; Greenwald, Nosek, \& Banaji, 2003). In one study, for example, participants belonging to a population concerned about weight-loss goals who engaged in high-level construal evaluated apples more positively than candy bars relative to those engaged in low-level construal (Fujita $\&$ Han, 2009). These differences in how participants performed on the IAT, moreover, mediated the effect of construal level on a subsequent preference for an apple versus a candy bar. Thus, construal level appears to impact self-control via changes in how people evaluate goal relevant-stimuli, and these changes in evaluation do not appear to require conscious deliberation. 


\section{Processes Involved in Implicit Evaluations}

Although the findings of Fujita and Han (2009) demonstrate that construal level can influence implicit evaluations, there is still little known about the processes that underlie this effect. For example, one might posit that highlevel (vs. low-level) construal reduces the influence of positive evaluative associations for temptations or increase the influence of positive associations for goal consistent stimuli. Alternatively, high-level (vs. low-level) construal may enhance relatively positive evaluations of goalrelevant stimuli by facilitating the ability to accurately identify and respond to such stimuli.

Initially, measures such as the IAT were designed to capture automatically activated evaluative associations. However, recent research has indicated that a number of other processes also contribute to IAT performance (e.g., Amodio, Devine, \& Harmon-Jones, 2008; Amodio et al., 2004; Conrey, Sherman, Gawronski, Hugenberg, \& Groom, 2005; Gonsalkorale et al., 2011; Sherman et al., 2008; Stewart \& Payne, 2008). One can use process dissociation (PD; Payne, 2008) to tease apart the contributions of these processes. Based on patterns of responding, the PD model independently estimates two parameters: $\mathrm{C}$ and $\mathrm{A}$. The $\mathrm{C}$ parameter represents the ability to intentionally identify and respond accurately to goal-relevant stimuli (e.g., correctly categorizing an apple as good, on an apple + good trial). In contrast, the A parameter represents responses driven by cognitive and evaluative associations without intention (i.e., producing an impulse to categorize an apple as good). According to the PD model, the processes captured by the A parameter are always active, but only drive responses in the absence of $\mathrm{C}$ (Payne, 2001). Thus, if the correct response is determined, it will be enacted. In this way, one can conceptualize the $\mathrm{C}$ parameter as the process that correctly identifies and responds to goal-relevant stimuli, and the A parameter as capturing a process that biases responses in either an accuracy-congruent or incongruent manner (depending on whether the trial is pairing compatible or incompatible concepts) when C fails.

Process dissociation has been widely implemented in research that is interested in independently measuring competing processes. For example, PD procedures have been applied to the domains of stereotyping (Amodio et al., 2004, 2008), moral psychology (Conway \& Gawronski, 2013), memory (Jacoby, 1991), and decision making (Damian \& Sherman, 2013; Ferreira, Garcia-Marques, Sherman, \& Sherman, 2006). In some cases, differences in the $\mathrm{C}$ parameter appear to be responsible for the outcomes of interest (i.e., racial bias, memory bias; Conway \& Gawronski, 2013; Damian \& Sherman, 2013; Govorun \& Payne, 2006; Jacoby, 1991; Stewart, von Hippel, \& Radvansky, 2009; Payne, 2001), whereas, in other cases, differences in the A parameter appear to be the driving factor (Mendoza, Gollwitzer, \& Amodio, 2010; Stewart \& Payne, 2008). Thus, the PD model has been applied successfully to distinguish between people who show bias on tasks because of failures of intentional responding versus unintentional influences (Payne, 2001; Govorun \& Payne, 2006).

\section{The Present Study}

In the present study, we apply a multinomial processing model (Batchelder \& Riefer, 1999) to IAT data from Fujita and Han (2009) to examine the contributions of intentional $(\mathrm{C})$ and unintentional (A) processes to changes in implicit evaluations produced by changes in construal level. Within A, high level construal might enhance the influence of positive associations with goal-consistent stimuli (apple-good A) or facilitate the influence of negative associations with temptations (cand-bad A). Highlevel construal may promote goal consistent evaluations by changing either of these A components, by changing $\mathrm{C}$, or by changing both. By employing this modeling technique, we aim to explicate the processes by which high level construal facilitates efficient goal pursuit, and contribute to a better understanding of the processes that underlie efficient self-regulation, more broadly.

\section{Method}

\section{Participants}

In the original study, across all three experiments, participants were female students from The Ohio State University. In exchange for participation, they were granted partial course credit. Experiment1 had 44 students, Experi- 
ment 2 had 86 students, and Experiment 3 had 91 students.

\section{Procedure and Materials}

Construal level manipulation. In all three experiments, construal level was manipulated using mindset priming procedures developed in previous research (Freitas, Gollwitzer, \& Trope, 2004; Fujita, Trope, Liberman, \& Levin-Sagi, 2006). Specifically, participants were asked to engage in an exercise designed to prime the abstraction versus concretization procedures associated with high-level versus low-level construal, respectively. In Experiment 1, participants were induced to engage in high-level versus low-level construal by being asked to list superordinate ends ("why") or subordinate means ("how") for the target behavior of "maintaining good personal relationships." In Experiments 2 and 3, participants were shown 40 objects (e.g., pasta), and were asked to generate a superordinate category label (e.g., food) versus subordinate exemplar (e.g., linguini) for each. Research indicates that procedurally priming high-level and low-level construal influences the construal of subsequent unrelated events (Freitas et al., 2004; Fujita et al., 2006).

IAT. All participants completed the apples versus candy bar IAT (Karpinski \& Hilton, 2001). Participants in the sample, on average, were concerned about weight loss, making the evaluation of healthy versus tempting food a motivationally relevant self-control domain. Using standard IAT protocol, participants completed practice trials categorizing apples (e.g., Fuji) and candy bars (e.g., Snickers) as well as valenced words (e.g., sickness; gift) as unpleasant or pleasant. After the practice trials, level of construal was manipulated. Following the construal level manipulation, participants performed the critical blocks pairing apples and candy bars with pleasantness or unpleasantness in counterbalanced order. To examine the relative preference for apples versus candy bars, the IAT $d$ score was calculated. Because they were easier for the participants to complete (e.g., participants made fewer errors and were quicker to respond), candy bar + bad/apples + good trials were considered compatible. Because they were more difficult to complete (e.g., participants made more errors and were slower to respond), candy bar + good/apple + bad trials were considered incompatible. As such, $d$ scores were coded so that higher numbers indicated greater ease in associating candy bar + bad/apples + good.

\section{Results}

The original study from Fujita and Han (2009) found that increasing construal level promotes more positive evaluations of apples relative to candy bars on the IAT. However, it is unclear how changing construal level influences evaluations at the process level. To address this question, we employed a variant of the process-dissociation model, process dissociation plus guessing $(\mathrm{PD}+\mathrm{G}) .{ }^{1} \mathrm{PD}+\mathrm{G}$ estimates $\mathrm{C}, \mathrm{A}$, and a guessing parameter $(\mathrm{G})$. The addition of a guessing parameter allows one to account for responses that are not due to $\mathrm{C}$ or $\mathrm{A}$. For example, in the absence of detection and selection of the correct response and when no evaluative associations are activated, participants may still have a bias to choose "pleasant" or "unpleasant" responses. When models do not account for the influence of guessing, all errors made in the bias-consistent direction (e.g., mistakenly categorizing an apple as good on an apple + bad trial) are attributed to unintentional processes, potentially inflating the A estimate (Burke, 2015). When the guessing parameter is added to the process dissociation model, the A parameter more precisely represents the extent to which unintentional processes drive responses.

The structure of this processing tree is demonstrated in Figure 1. In the processing tree, each path represents a likelihood of a given process driving a response on a trial. Parameters with lines leading to them are conditional on preceding parameters (e.g., guessing is conditional, depending on $\mathrm{A}$ and $\mathrm{C}$ ). These conditional relationships create a system of equations that can be used to predict correct and incorrect responses based on trial type (i.e., compatible and incompatible trials). For example, on an

\footnotetext{
${ }^{1}$ In addition to conceptual reasons, such as the possible inflation of A estimates in using a model without a guessing parameter (Burke, 2015), we chose the PD + G model over PD and the Quad model (Sherman et al., 2008) based on comparisons of model fit, according to Minimum Description Length (Wu, Myung, \& Batchelder, 2010). Model fits are reported in Table 1.
} 


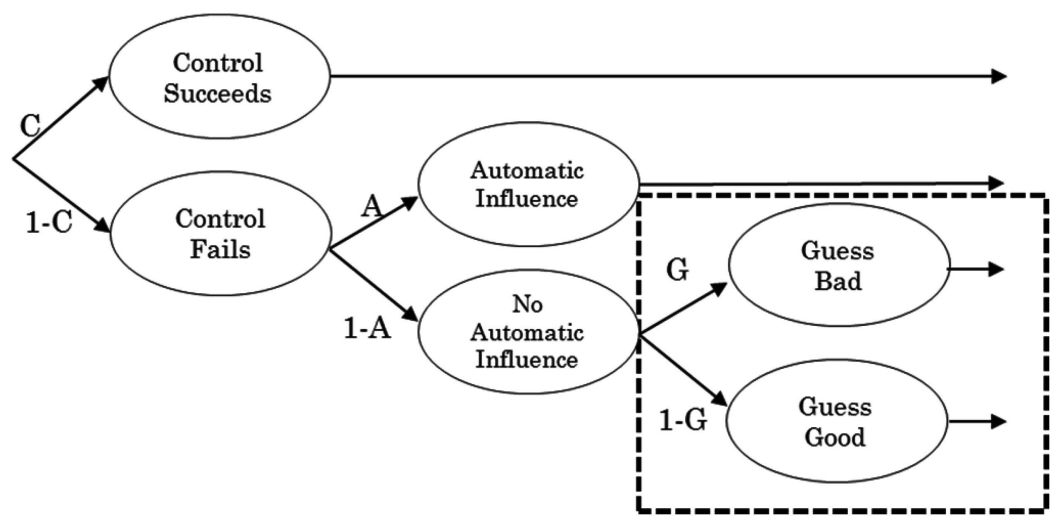

Figure 1. Multinomial processing tree for process dissociation plus guessing.

apple compatible trial, the probability of a correct response can be obtained with the probability: $\mathrm{C}+(1-\mathrm{C})^{*} \mathrm{~A}+(1-\mathrm{C})^{*}(1-\mathrm{A})^{*}(1-\mathrm{G})$. This equation represents the possible ways by which a participant can make a correct response on a given trial. The first part of the equation, $\mathrm{C}$, represents the probability that the correct answer is intentionally detected and implemented by the participant. On a compatible trial, a participant may fail to detect the correct answer but may still make the correct response due to the unintentional influence of activated associations between apple and pleasant, represented by $(1-\mathrm{C})^{*} \mathrm{~A}$. In the absence of detecting the correct answer or using activated associations between apple and pleasant, a participant may still give the correct answer by guessing pleasant $(1-C)^{*}$ $(1-\mathrm{A})^{*}(1-\mathrm{G})$. The equations for each item type (candy, apples, pleasant words, and unpleasant words in both the compatible and incompatible blocks) are then used to predict the errors observed in the data. Using a maximum likelihood procedure, parameter values are estimated until reaching the smallest possible chi square value. The obtained chi square value represents the difference between the observed and predicted pattern of errors (Cohen, 1988). The parameter estimates themselves represent the extent to which each process contributes to the pattern of errors and correct answers observed in the IAT data.

To investigate the processes underlying the effect of construal level on performance on the apples versus candy IAT, we obtained parameter estimates for both the low-level and highlevel construal conditions for all studies. The model fit well across all studies, suggesting that the PD + G model was appropriate to explain the data. In Experiment 1, the chi-square for model fit was $\chi^{2}=.05, p=.973$. Experiments 2 and 3 had identical procedures and results and, as such, were combined to maximize the power of the model estimates, $\chi^{2}=3.51, p=$ .172 .

In both Experiment 1 and combined Experiments 2 and 3 there were significant differences between the high and low-level conditions on the C parameter. Specifically, participants engaged in high-level construal had greater $\mathrm{C}$ estimates relative to participants engaged in lowlevel construal, Experiment $1 \Delta \chi^{2}=3.43, p=$ .064 ; Experiment $2 \& 3 \Delta \chi^{2}=6.57, p=.010$ (see Table 2 for descriptive statistics). In addition, in combined Experiments 2 and 3, the high-level construal had a higher A estimate $(M=.09, S E=.03)$ than the low-level construal condition $(M=.00, S E=.03), \Delta \chi^{2}=$ $7.08, p=.008$. However, the A estimates in Experiment 1 did not differ based on construal level, $\Delta \chi^{2}=.14, p=.708$.

Although construal level appeared to change the involvement of unintentional processes, the basic PD $+G$ model cannot test which activated associations were driving responses. That is, an increase in A processes on this task can stem from the unintentional influence of associations between apples and pleasantness (apple-good A) or between candy bars and unpleasantness (cand-bad A). In order to examine these different possibilities in Experiments 2 and 3, we employed a PD + G model with two separate A parameters, one representing the in- 
Table 1

Parameter Estimates by Experiment

\begin{tabular}{lcc}
\hline \multicolumn{1}{c}{ Parameter } & High level & Low level \\
\hline C & Experiment 1 & \\
A & $.90(.01)[.89, .92]$ & $.88(.01)[.87, .90]$ \\
Apple-good A & $.04(.08)[-.12, .20]$ & $.00(.07)[-.14, .14]$ \\
Candy-bad A & $.13(.35)[-.56, .81]$ & $.00(.38)[-.75, .75]$ \\
G & $.00(.29)[-.57, .81]$ & $.02(.29)[-.55, .59]$ \\
& $.39(.04)[.31, .47]$ & $.44(.04)[.37, .51]$ \\
C & Experiment 2 and 3 & \\
A & $.88(.01)[.87, .88]$ & $.86(.01)[.85, .87]$ \\
Apple-good A & $.09(.03)[.03, .16]$ & $.00(.03)[-.06, .06]$ \\
Candy-bad A & $.12(.12)[-.12, .36]$ & $.00(.13)[-.26, .26]$ \\
G & $.07(.12)[.15, .30]$ & $.00(.13)[-.26, .26]$ \\
& $.46(.02)[.43, .50]$ & $.47(.02)[.44, .51]$ \\
C & All experiments combined & \\
A & $.88(.01)[.87, .89]$ & $.86(.01)[.86, .87]$ \\
Apple-good A & $.09(.03)[.03, .14]$ & $.00(.03)[-.06, .06]$ \\
Candy-bad A & $.12(.12)[-.12, .36]$ & $.00(.03)[-.06, .06]$ \\
G & $.06(.11)[-.17, .28]$ & $.00(.12)[-.23, .23]$ \\
\hline Note. Stand $]$ & $.45(.02)[.42, .48]$ & $.47(.01)[.44, .50]$ \\
\hline
\end{tabular}

Note. Standard errors are in parentheses, and $95 \%$ confidence intervals in brackets.

fluence of apple/good associations (apple-good A) and another representing the influence of candy bars/bad associations (cand-bad A). ${ }^{2}$ The cand-bad A estimate did not differ across groups, $\Delta \chi^{2}=1.80, p=.180$. However, the apple-good A estimate was greater $(M=.12$, $S E=.12)$ in the high-level construal condition than in the low-level construal condition $(M=$ $.00, S E=.13$ ) $, \Delta \chi^{2}=4.46, p=.035$ (see Table 2 for descriptive statistics). These findings indicate that high level construal increases the unintended influence of positive goal-relevant associations.

\section{General Discussion}

Altering evaluations of goal-relevant stimuli in a goal-congruent direction facilitates goal-congruent behavior (Fujita, 2008; Fujita \& Carnevale, 2012). Prior research has found that construal level can influence how people evaluate goal-relevant stimuli, even when they have limited time and resources to deliberate about their evaluations (Carnevale, Fujita, Han, \& Amit, 2015; Fujita \& Han, 2009). To date, however, there has been little investigation into the processes by which construal influences evaluation. The current re- search used a multinomial model to investigate the role of key processes involved in implicit evaluation. Our analyses suggest that construal level influences implicit evaluation by increasing the unintended influence of positive goal-consistent associations (apple + good), as well as by enhancing the ability to intentionally detect and accurately respond to goal-relevant stimuli.

Our results are consistent with the findings of past work on motivation and racial bias. Specifically, individuals with strongly held goals to avoid being prejudiced (high IMS/ low EMS; Devine et al., 2002) tend to show lower bias on the race IAT. Such lowered bias is associated with lower Black-bad and White-good associations, in addition to increased detection of correct responses (Gonsalkorale et al., 2011). The fact that changes

\footnotetext{
${ }^{2} \mathrm{~A}$ PD $+\mathrm{G}$ model with $2 \mathrm{~A}$ parameters is initially a model that has 0 degrees of freedom. Without a degree of freedom, one cannot compare parameter estimates across construal-level groups. To gain one degree of freedom, we set the $G$ parameter to be equal across groups. It was appropriate to set the $\mathrm{G}$ parameters equal, given that across all studies, the construal groups did not differ in their $G$ estimate.
} 
Table 2

Fit Statistics by Experiment

\begin{tabular}{lrrrr}
\hline Experiment and model & $\chi^{2}$ & MDL & AIC & BIC \\
\hline Experiment 1 & & & & \\
$\quad$ Quad model & 20.94 & $1,251.85$ & $2,472.12$ & $2,538.99$ \\
PD + G & 0.05 & $1,246.25$ & $2,466.86$ & $2,506.98$ \\
PD & 9.06 & $1,246.05$ & $2,471.86$ & $2,498.61$ \\
Experiment 2 and 3 & & & $13,614.59$ & $16,171.82$ \\
$\quad$ Quad model & 129.81 & $6,824.67$ & $13,613.44$ & $13,662.89$ \\
PD + G & 3.51 & $6,824.20$ & $13,615.70$ & $13,648.67$ \\
PD & 9.78 & $6,821.08$ & \\
Note. Lower numbers indicate better fit to data. MDL = minimum description length; \\
AIC = Akaike information criterion; BIC = Bayes information criterion; PD = process \\
dissociation; PD + G = process dissociation plus guessing.
\end{tabular}

in detection and association-related processes were observed in both Gonsalkorale et al. (2011) and in the current work may suggest something general about the processes underlying successful goal pursuit. In particular, goal consistent evaluation of stimuli in contexts allowing minimal deliberation (e.g., goal-consistent evaluations on the IAT) may stem from both changes in the impact of unintentional processes and the ability to intentionally detect and accurately respond to goalrelevant stimuli. These findings are also consistent with the suggestion that high-level construal promotes control by enhancing the identification and implementation of thoughts and behaviors that are goal-consistent. This form of control does not appear to require a great deal of mental resources or deliberation (Amodio et al., 2008; Bartholow, Dickter, \& Sestir, 2006; Correll, Urland, \& Ito, 2006).

It is unclear why the results of Experiment 1 differ from the results of Experiment 2 and 3. One possible reason is that the construal level manipulation used in Experiment 1 differed from the later experiments. Experiment 1 also had the smallest sample size of all 3 experiments. To address this, we ran an additional analysis combining all studies to maximize power to detect effects. The model fit well, $\chi^{2}=$ $3.17, p=.205$, suggesting that the model was appropriate to explain the data. Mirroring the results of combined Experiments 2 and 3, the $\mathrm{C}$ estimate was higher in the high-level construal condition $(M=.88, S E=.01)$ than the lowlevel condition $(M=.86, S E=.01), \Delta \chi^{2}=$ 9.06, $p=.003$. In addition, there was a higher A estimate for the high-level condition, $(M=$
$.09, S E=.03)$ relative to the low-level condition $(M=.00, S E=.03), \Delta \chi^{2}=6.72, p=$ .010 , which was again driven by a higher applegood A estimate (high-level $M=.12, S E=.12$, low-level $M=.00, S E=.03), \Delta \chi^{2}=5.23, p=$ .022 . These findings suggest that, overall, highlevel construal facilitated implicit goal pursuit by increasing both $\mathrm{C}$ and $\mathrm{A}$.

\section{Limitations and Future Directions}

Although we found that high-level construal increased the influence of apple-good associations, this particular IAT elicits relatively low bias. Low estimates of A may be a limitation of the apples versus candy bar IAT. In particular, IAT scores (proapple/anticandy bar bias) on the apples versus candy bar IAT tend to be lower than other IATs, such as the race IAT (prowhite/antiblack bias). In fact, in the original implementation of the apples versus candy bar IAT, as well as in Fujita and Han (2009), participants had relatively more positive evaluations of apples than of candy bars (Karpinski \& Hilton, 2001). Thus, the current data measure the extent of goalconsistent evaluations on a task that already favors goal-consistent evaluations. It is possible that the processes by which construal level impacts evaluations could differ in domains in which compatible trials are inconsistent with global goals. To address this question, further work should use comparison categories that more strongly activate associations that conflict with participants' goals (Carnevale et al., 2015). Such a follow-up could also expand our understanding of 
whether construal level only increases the influence of goal-consistent associations or whether it can also decrease the influence of goal-inconsistent ones.

Another possible limitation concerns whether the effect of construal level on implicit evaluations truly reflects goal-relevant responses. Given that female undergraduates on average tend to report being concerned with weight-loss, we believe that it is reasonable to assume that apples versus candy bars represents a motivationally relevant self-control dilemma. Nevertheless, in keeping with other research examining the effect of construal level on self-control (Carnevale et al., 2015; Fujita \& Sasota, 2011; Fujita et al., 2006), demonstrating that these effects are specific to those for whom the selfcontrol domain is motivationally relevant (vs. not relevant) is an important future direction.

\section{Implications}

One extension to our understanding of the effects of construal level on self-control is our apple-good A finding. In particular, high-level construal increased the influence of apple-good associations. Although research on construal level and self-control has frequently found that construal level impacts preferences (Fujita \& Han, 2009), it has, at times, been unclear in which direction preferences were being moved. Specifically, it has been difficult to determine whether high-level construal decreases preference for local stimuli or increases preference for stimuli that facilitate global goals. In the current study, high-level construal promoted the influence of positive goal-consistent associations.

High-level construal also promoted successful goal pursuit by enhancing the ability to detect and accurately respond to goal-relevant stimuli. Thus, these findings support the assertion that construal level may promote selfcontrol via intentional mechanisms that, nevertheless, do not require the slow and resourcedemanding processes that most dual-process and dual-systems models of self-control posit. Our findings build on a growing body of evidence that goal-relevant intentional processes can be accomplished very efficiently, even when responding on implicit measures (e.g., Fishbach et al., 2010; Fishbach \& Shah, 2006; Moskowitz \& Li, 2011; Moskowitz, Salomon,
\& Taylor, 2000; Payne, 2001; Sherman et al., 2008).

Overall, our modeling results contribute to a better understanding of how construal level operates on mental processes, which may offer insight into when increasing construal level might be most effective for facilitating selfcontrol (Schmeichel, Vohs, \& Duke, 2011). Our $\mathrm{C}$ parameter results suggest that increasing construal level may be particularly effective when participants have a difficult time accurately identifying goal-relevant stimuli and responding to them appropriately (Fishbach \& Converse, 2010; Myrseth \& Fishbach, 2009). Any intervention that targets construal level, for example, may be especially effective when people are first adopting new goals and are less adept at identifying and evaluating goal-relevant stimuli and behavior. At the same time, the changes in influence of associations suggest that increasing construal level may be especially helpful for increasing the perceived positivity of goalconsistent stimuli in the first place (Fujita \& Roberts, 2010). This also suggests that highlevels of construal may be most helpful for promoting the approach of goal consistent stimuli, rather than avoiding stimuli that are disruptive to global goal pursuit.

\section{Conclusion}

Although some research on self-control finds that goal pursuit is challenging and reliant on limited resources (Baumeister, Bratslavsky, Muraven, \& Tice, 1998; Baumeister, Vohs, \& Tice, 2007; Hofman et al., 2009), other findings allow for more optimism. There is evidence for goals impacting the evaluation of tempting stimuli even when deliberation is limited (Carnevale et al., 2015; Fishbach et al., 2010; Fujita \& Han, 2009). Such evaluations have been linked to meaningful self-control behavior, suggesting that less positive evaluations of tempting stimuli may predict better self-control. The current research furthers our understanding of how construal levels change the evaluation of tempting stimuli by investigating the underlying processes. Our findings suggest that high level construal increases the influence of positive goal-relevant associations and facilitates accurate detection and responding to goal-relevant stimuli. Both of these processes have been 
linked to behavior that promotes global-goal pursuit.

\section{References}

Ainslie, G. (1975). Specious reward: A behavioral theory of impulsiveness and impulse control. Psychological Bulletin, 82, 463-496. http://dx.doi .org/10.1037/h0076860

Amodio, D. M., Devine, P. G., \& Harmon-Jones, E. (2008). Individual differences in the regulation of intergroup bias: The role of conflict monitoring and neural signals for control. Journal of Personality and Social Psychology, 94, 60-74. http://dx .doi.org/10.1037/0022-3514.94.1.60

Amodio, D. M., Harmon-Jones, E., Devine, P. G., Curtin, J. J., Hartley, S. L., \& Covert, A. E. (2004). Neural signals for the detection of unintentional race bias. Psychological Science, 15, 88-93. http:// dx.doi.org/10.1111/j.0963-7214.2004.01502003.x

Bartholow, B. D., Dickter, C. L., \& Sestir, M. A. (2006). Stereotype activation and control of race bias: Cognitive control of inhibition and its impairment by alcohol. Journal of Personality and Social Psychology, 90, 272-287. http://dx.doi.org/10 $.1037 / 0022-3514.90 .2 .272$

Batchelder, W. H., \& Riefer, D. M. (1999). Theoretical and empirical review of multinomial process tree modeling. Psychonomic Bulletin \& Review, 6, 57-86. http://dx.doi.org/10.3758/BF03210812

Baumeister, R. F., Bratslavsky, E., Muraven, M., \& Tice, D. M. (1998). Ego depletion: Is the active self a limited resource? Journal of Personality and Social Psychology, 74, 1252-1265. http://dx.doi .org/10.1037/0022-3514.74.5.1252

Baumeister, R. F., Vohs, K. D., \& Tice, D. M. (2007). The strength model of self-control. Current Directions in Psychological Science, 16, 351355. http://dx.doi.org/10.1111/j.1467-8721.2007 $.00534 . \mathrm{x}$

Burke, C. T. (2015). Process dissociation models in racial bias research: Updating the analytic method and integrating with signal detection approaches. Group Processes \& Intergroup Relations, 18, 402434. http://dx.doi.org/10.1177/1368430214567763

Carnevale, J. J., Fujita, K., Han, H. A., \& Amit, E. (2015). Immersion versus transcendence: How pictures and words impact evaluative associations assessed by the Implicit Association Test. Social Psychological and Personality Science, 6, 92-100. http://dx.doi.org/10.1177/1948550614546050

Cohen, J. (1988). Chi-square tests for goodness of fit and contingency tables. Statistical Power Analysis for the Behavioral Sciences, 2, 215-271.

Conrey, F. R., Sherman, J. W., Gawronski, B., Hugenberg, K., \& Groom, C. J. (2005). Separating multiple processes in implicit social cognition: The quad model of implicit task performance. Journal of Personality and Social Psychology, 89, 469487. http://dx.doi.org/10.1037/0022-3514.89.4 .469

Conway, P., \& Gawronski, B. (2013). Deontological and utilitarian inclinations in moral decision making: a process dissociation approach. Journal of Personality and Social psychology, 104, 216-235.

Correll, J., Urland, G. R., \& Ito, T. A. (2006). Eventrelated potentials and the decision to shoot: The role of threat perception and cognitive control. Journal of Experimental Social Psychology, 42, 120-128. http://dx.doi.org/10.1016/j.jesp.2005.02 .006

Damian, R. I., \& Sherman, J. W. (2013). A processdissociation examination of the cognitive processes underlying unconscious thought. Journal of Experimental Social Psychology, 49, 228-237.

Devine, P. G., Plant, E. A., Amodio, D. M., HarmonJones, E., \& Vance, S. L. (2002). The regulation of explicit and implicit race bias: The role of motivations to respond without prejudice. Journal of Personality and Social Psychology, 82, 835-848. http://dx.doi.org/10.1037/0022-3514.82.5.835

Ferreira, M. B., Garcia-Marques, L., Sherman, S. J., \& Sherman, J. W. (2006). Automatic and controlled components of judgment and decision making. Journal of Personality and Social Psychology, 91, 797-813. http://dx.doi.org/10.1037/0022-3514 .91 .5 .797

Fishbach, A., \& Converse, B. A. (2010). Identifying and battling temptation. In K. D. Vohs \& R. F. Baumeister (Eds.), Handbook of self-regulation: Research, theory and applications (2nd ed., pp. 244-260). New York, NY: Guilford Press.

Fishbach, A., \& Shah, J. Y. (2006). Self-control in action: Implicit dispositions toward goals and away from temptations. Journal of Personality and Social Psychology, 90, 820-832. http://dx.doi.org/ 10.1037/0022-3514.90.5.820

Fishbach, A., Zhang, Y., \& Trope, Y. (2010). Counteractive evaluation: Asymmetric shifts in the implicit value of conflicting motivations. Journal of Experimental Social Psychology, 46, 29-38. http://dx.doi.org/10.1016/j.jesp.2009.09.008

Freitas, A. L., Gollwitzer, P., \& Trope, Y. (2004). The influence of abstract and concrete mindsets on anticipating and guiding others' self-regulatory efforts. Journal of Experimental Social Psychology, 40, 739-752. http://dx.doi.org/10.1016/j.jesp.2004 .04 .003

Fujita, K. (2008). Seeing the forest beyond the trees: A construal-level approach to self-control. Social and Personality Psychology Compass, 2, 14751496. http://dx.doi.org/10.1111/j.1751-9004.2008 .00118.x

Fujita, K. (2011). On conceptualizing self-control as more than the effortful inhibition of impulses. Per- 
sonality and Social Psychology Review, 15, 352366. http://dx.doi.org/10.1177/1088868311411165

Fujita, K., \& Carnevale, J. J. (2012). Transcending temptation through abstraction: The role of construal level in self-control. Current Directions in Psychological Science, 21, 248-252. http://dx.doi .org/10.1177/0963721412449169

Fujita, K., \& Han, H. A. (2009). Moving beyond deliberative control of impulses: The effect of construal levels on evaluative associations in selfcontrol conflicts. Psychological Science, 20, 799804. http://dx.doi.org/10.1111/j.1467-9280.2009 .02372.x

Fujita, K., \& Roberts, J. C. (2010). Promoting prospective self-control through abstraction. Journal of Experimental Social Psychology, 46, 10491054. http://dx.doi.org/10.1016/j.jesp.2010.05.013

Fujita, K., \& Sasota, J. A. (2011). The effects of construal levels on asymmetric temptation-goal cognitive associations. Social Cognition, 29, 125146. http://dx.doi.org/10.1521/soco.2011.29.2.125

Fujita, K., Trope, Y., Liberman, N., \& Levin-Sagi, M. (2006). Construal levels and self-control. Journal of Personality and Social Psychology, 90, 351367. http://dx.doi.org/10.1037/0022-3514.90.3 .351

Gonsalkorale, K., Sherman, J. W., Allen, T. J., Klauer, K. C., \& Amodio, D. M. (2011). Accounting for successful control of implicit racial bias: The roles of association activation, response monitoring, and overcoming bias. Personality and Social Psychology Bulletin, 37, 1534-1545. http://dx .doi.org/10.1177/0146167211414064

Govorun, O., \& Payne, B. K. (2006). EgoDepletion and prejudice: Separating automatic and controlled components. Social Cognition, 24, 111136. http://dx.doi.org/10.1521/soco.2006.24.2.111

Greenwald, A. G., Nosek, B. A., \& Banaji, M. R. (2003). Understanding and using the implicit association test: I. An improved scoring algorithm. Journal of Personality and Social Psychology, 85, 197-216. http://dx.doi.org/10.1037/0022-3514.85 .2 .197

Hinson, J. M., Jameson, T. L., \& Whitney, P. (2003). Impulsive decision making and working memory. Journal of Experimental Psychology: Learning, Memory, and Cognition, 29, 298-306. http://dx .doi.org/10.1037/0278-7393.29.2.298

Hofmann, W., Friese, M., \& Strack, F. (2009). Impulse and self-control from a dual-systems perspective. Perspectives on Psychological Science, 4, 162-176. http://dx.doi.org/10.1111/j.1745-6924 .2009.01116.x

Inzlicht, M., \& Gutsell, J. N. (2007). Running on empty: Neural signals for self-control failure. Psychological Science, 18, 933-937. http://dx.doi.org/ 10.1111/j.1467-9280.2007.02004.x
Jacoby, L. L. (1991). A process dissociation framework: Separating automatic from intentional uses of memory. Journal of Memory and Language, 30, 513-541.

Karpinski, A., \& Hilton, J. L. (2001). Attitudes and the Implicit Association Test. Journal of Personality and Social Psychology, 81, 774-788. http:// dx.doi.org/10.1037/0022-3514.81.5.774

Mendoza, S. A., Gollwitzer, P. M., \& Amodio, D. M. (2010). Reducing the expression of implicit stereotypes: Reflexive control through implementation intentions. Personality and Social Psychology Bulletin, 36, 512-523.

Mischel, W., Shoda, Y., \& Rodriguez, M. I. (1989). Delay of gratification in children. Science, 244, 933-938. http://dx.doi.org/10.1126/science.2658056

Moskowitz, G. B. (2002). Preconscious effects of temporary goals on attention. Journal of Experimental Social Psychology, 38, 397-404. http://dx .doi.org/10.1016/S0022-1031(02)00001-X

Moskowitz, G. B., Gollwitzer, P. M., Wasel, W., \& Schaal, B. (1999). Preconscious control of stereotype activation through chronic egalitarian goals. Journal of Personality and Social Psychology, 77, 167-184. http://dx.doi.org/10.1037/0022-3514.77 .1 .167

Moskowitz, G. B., \& Li, P. (2011). Egalitarian goals trigger stereotype inhibition: A proactive form of stereotype control. Journal of Experimental Social Psychology, 47, 103-116. http://dx.doi.org/10 .1016/j.jesp.2010.08.014

Moskowitz, G. B., Salomon, A. R., \& Taylor, C. M. (2000). Preconsciously controlling stereotyping: Implicitly activated egalitarian goals prevent the activation of stereotypes. Social Cognition, 18, 151-177. http://dx.doi.org/10.1521/soco.2000.18 .2 .151

Muraven, M., \& Baumeister, R. F. (2000). Selfregulation and depletion of limited resources: Does self-control resemble a muscle? Psychological Bulletin, 126, 247-259. http://dx.doi.org/10.1037/ 0033-2909.126.2.247

Myrseth, K. O. R., \& Fishbach, A. (2009). Selfcontrol: A function of knowing when and how to exercise restraint. Current Directions in Psychological Science, 18, 247-252. http://dx.doi.org/10 .1111/j.1467-8721.2009.01645.x

Payne, B. K. (2001). Prejudice and perception: The role of automatic and controlled processes in misperceiving a weapon. Journal of Personality and Social Psychology, 81, 181-192. http://dx.doi.org/ 10.1037/0022-3514.81.2.181

Payne, B. K. (2008). What mistakes disclose: A process dissociation approach to automatic and controlled processes in social psychology. Social and Personality Psychology Compass, 2, 1073 1092. http://dx.doi.org/10.1111/j.1751-9004.2008 .00091.x 
Schmeichel, B. J., Vohs, K. D., \& Duke, S. C. (2011). Self-control at high and low levels of mental construal. Social Psychological and Personality Science, 2, 182-189. http://dx.doi.org/10.1177/1948 550610385955

Sherman, J. W., Gawronski, B., Gonsalkorale, K., Hugenberg, K., Allen, T. J., \& Groom, C. J. (2008). The self-regulation of automatic associations and behavioral impulses. Psychological Review, 115, 314-335. http://dx.doi.org/10.1037/ 0033-295X.115.2.314

Shiv, B., \& Fedorikhin, A. (1999). Heart and mind in conflict: The interplay of affect and cognition in consumer decision making. The Journal of Consumer Research, 26, 278-292. http://dx.doi.org/10 $.1086 / 209563$

Stewart, B. D., \& Payne, B. K. (2008). Bringing automatic stereotyping under control: Implementation intentions as efficient means of thought control. Personality and Social Psychology Bulletin, 34, 1332-1345. http://dx.doi.org/10.1177/0146 167208321269

Stewart, B. D., von Hippel, W., \& Radvansky, G. A. (2009). Age, race, and implicit prejudice: Using process dissociation to separate the underlying components. Psychological Science, 20, 164-168.

Strack, F., \& Deutsch, R. (2004). Reflective and impulsive determinants of social behavior. Personality and Social Psychology Review, 8, 220-247. http://dx.doi.org/10.1207/s15327957pspr0803_1

Torelli, C. J., \& Kaikati, A. M. (2009). Values as predictors of judgments and behaviors: The role of abstract and concrete mindsets. Journal of Personality and Social Psychology, 96, 231-247. http:// dx.doi.org/10.1037/a0013836

Trope, Y., \& Liberman, N. (2010). Construal-level theory of psychological distance. Psychological Review, 117, 440-463. http://dx.doi.org/10.1037/ a0018963

Wu, H., Myung, J. I., \& Batchelder, W. H. (2010). Minimum description length model selection of multinomial processing tree models. Psychonomic Bulletin \& Review, 17, 275-286. http://dx.doi.org/ 10.3758/PBR.17.3.275

Received June 20, 2017 Revision received October 26, 2017 Accepted October 29, 2017 


\section{AUTHOR QUERIES}

\section{AUTHOR PLEASE ANSWER ALL QUERIES}

AQau-Please confirm the given-names and surnames are identified properly by the colors. = Given-Name, $\boldsymbol{a}=$ Surname The colors are for proofing purposes only. The colors will not appear online or in print.

AQ1-Author: Please provide a shortened article title (50 characters or fewer, including spaces) to serve as the running head.

AQ2-Author: Please provide a reference entry for the following citations in this paragraph or confirm that they can be deleted from the text: Conway \& Gawronski, 2013; Jacoby, 1991; Damian \& Sherman, 2013; Stewart et al., 2009; Mendoza et al., 2010.

AQ3-Author: Tables should be mentioned in the text in the order in which they appear. Please indicate whether we should renumber Tables 1 and 2 or whether you would like to mention Table 1 before here.

AQ4-Author: Please provide departmental affiliations for all authors. 